\title{
O PALÁCIO E O CONSENSO: O OFFICIUM PALATINUM E A ARTICULAÇÃO DA ARISTOCRACIA VISIGODA (SÉCULOS VI-VIII)
}

\section{EDUARDO CARDOSO DAFLON*}

Resumo: A chamada Hispânia Visigótica foi, sem dúvida, uma sociedade estratificada e cindida. Não só em distintas classes sociais - sendo a aristocracia e o campesinato as duas principais -, mas também do ponto de vista das disputas internas às classes, algo que pode ser percebido pelas tensões intermitentes das quais a documentação nos dá apenas algumas pistas. Estes conflitos internos, no que diz respeito à aristocracia, são mais evidentes no contexto das constantes disputas pelo trono régio, porém se manifestam frequentemente nos conflitos pelo controle de patrimônio fundiário e dos dependentes. Em suma, a fim de amortecer e tentar controlar estes choques internos, podemos vislumbrar a existência de mecanismos privilegiados de articulação dos grupos dominantes, sendo um deles o palácio régio ou, como muitas vezes referido nos documentos de época, o Officium Palatinum. Assim, consiste em um dos objetivos fundamentais deste trabalho esboçar uma caracterização deste âmbito de articulação, bem como explicitar os níveis de dominação por ele propiciado.

Palavras chave: Espanha Visigoda; Officium Palatinum; Consenso.

\section{The palace and the consensus: the Officium Palatinum and the visigothic aristocracy articulation (VI-VIII centuries)}

\begin{abstract}
The so called Visigothic Spain was, certainly, a stratified society, not only in social classes - being the aristocracy and the peasantry the mains ones - but also through the perspective of the tensions and conflicts inside the classes. It is possible to observe this process thanks to the context of constant dispute among the aristocrats for acess to land, labor and, at a higher level, the crown itself. Those referred tensions, among the aristocracy, may be best seen in the frequent conflicts to control the throne, but also during the disputes for land patrimony and dependent peasants. In summary, aiming to soft and restrict internal shocks, it is possible to see the existence of articulation mechanisms inside the dominant groups. One of then is the king's palace or, as referred in the primary sources, the Officium Palatinum. Therefore, this paper main objective is to propose a characterization of such articulation as well to offer an explanation about the domination levels that it propicies.
\end{abstract}

Palavras chave: Visigotic Spain; Officium Palatinum; Consense.

O presente texto, cabe destacar, antes de qualquer outra referência, parte de algumas perspectivas teóricas que orientaram minha interpretação do contexto Visigodo. Parto da noção de que as sociedades humanas que superam o caráter tribal demandam um conjunto de relações sociais que excedem a esfera familiar para se organizarem, conformando uma estrutura estatal historicamente configurada. Assim sen-

\footnotetext{
* Doutorando em História Social na Universidade Federal Fluminenese (UFF). Bolsista do CNPq.
} 
do, defendo que havia um Estado na Alta Idade Média, em específico para a Península Ibérica sob o controle visigótico.

Os membros da aristocracia precisavam, para manter seu apoio político e se manterem como poderes locais ou regionais, redistribuir para seus fiéis as finitas fontes de riqueza que havia. Assim, sendo a terra e o trabalho camponês limitados, era necessário que constantemente alargassem seus domínios a fim de redistribuí-los, estando, pois, inseridos no contexto da necessidade de uma reprodução expansiva, como bem percebeu Pablo Díaz (2012). Desse modo, como veremos em detalhe mais a frente, compor e mesmo orbitar Officum Palatinum era uma dessas formas de garantir a reprodução ampliada de setores da aristocracia, frequentemente, em detrimento de outros aristocratas ou mesmo do rei ou do fisco régio.

Nesse sentido, podemos observar que havia espaços privilegiados - ainda que não únicos - onde se davam os conflitos entre a aristocracia visigoda. Sendo assim, não pretendo neste artigo fazer um inventário dos postos da administração visigoda, como já feito anteriormente, pois penso que uma análise que seguisse esse rumo não redundaria em uma explicação sobre o Estado. Ainda que seja um estudo importante, a meu ver está excessivamente ligado a uma perspectiva que personaliza e isola os membros de uma administração, recaindo em uma espécie de individualismo metodológico. Tira-se, dessa forma, o foco dos agentes coletivos que são as classes e, consequentemente, das tensões e conflitos que a interação entre esses agentes coletivos podia gerar. Essa visão com o fim de mapear os "gestores" do Estado está também fortemente ligada à forte tradição juridicista da historiografia espanhola, acabando por atribuir à "corrupção" ou ao "mau funcionamento" qualquer não correspondência do real em relação às proposições ideais manifestas em um texto normativo.

Desejo abarcar aqui, conforme já dito, um dos espaços coletivos que articularam, em conflituosa conjunção, ao menos parte das diversas frações da aristocracia visigoda, o chamado palácio régio. ${ }^{1}$ Dito isso, penso que cabe ressaltar que, ainda que haja uma série de vocábulos que constantemente aparecem nas fontes visigodas, tais como palatium ou officium palatinum, que remetem àquilo que poderia ser traduzido como "palácio", todavia, dificilmente esta palavra significava de forma literal um pré-

\footnotetext{
${ }^{1}$ Outro espaço de apaziguamento dos conflitos no contexto da Hispânia Visigoda são concílios. Discuti esse elemento em: Daflon, 2016: 110-119.
} 
dio estabelecido em Toledo, onde residia o rei. Não se tratava fundamentalmente de um substantivo concreto, mas antes abstrato, do qual menos importavam seus muros e pedras do que um locus da articulação de parte da aristocracia com o rei. Tratar-seia, portanto, daquilo que chamei de instituição no quadro da sociedade visigótica, e que desempenhou um papel expressivo, dado sua perene e grande presença nos corpora documentais estudados.

Contudo, alguns historiadores que se dedicaram a analisar o palatium tiveram pouco consenso acerca de sua configuração e organização. Convém, então, sistematizar algumas das referências mais importantes da historiografia para que possamos avançar algumas críticas e, na sequência, proposições.

Talvez o estudo mais pormenorizado do palácio tenha sido realizado por Cláudio Sánchez-Albornoz (1971) em princípios da década de 1970, traçando uma linha de continuidade entre as assembleias de homens livres da Germânia da época de Tácito com as que se realizaram entre os séculos V e VII. Para ele, os godos ainda mantiveram a prática de reunirem-se mesmo após o assentamento na Gália, e até posteriormente na Hispânia, ainda que seu número tenha se reduzido consideravelmente pela dificuldade de reunir os homens livres dispersos pelo território.

Para justificar essa posição o autor se baseia em uma série de escritores antigos, que dariam indícios da manutenção dessas reuniões de homens livres, ainda que cada vez mais esparsas no tempo. Jordanes, por exemplo, que nos fala que, em momentos de tomada em armas, algumas dessas assembleias teriam acontecido. Por exemplo, quando o rei Teodoredo morreu na Batalha dos Campos Catalúnicos, o exército aclamou pelas armas a Turismundo, supostamente seguindo a antiga tradição germânica. Além disso, sabemos, por Procópio, que o exército obrigou o rei Alarico II a uma batalha campal com os francos contra sua vontade, o que implicaria a celebração de uma assembleia popular. Claudiano, em seu poema De bello Gothico, nos dá notícia da consulta de um ancião pelo rei Alarico, em 402, sobre uma batalha com Roma, que o autor sinaliza como outra evidência de que se trataria da manutenção das assembleias. Sidônio Apolinário, no Panegyricus Avito Augusto, de junho de 455, refere-se à ida de seu genro, e futuro imperador romano, Avito, à corte do rei godo Teodorico, filho do vencedor dos hunos, buscando apoio do exército godo a Roma no momento em que a cadeira imperial estava vacante. Teodorico, favorável, reúne os anciãos go- 
dos naquilo que Sidônio chamou de concilium. Mais um exemplo, colhido na Chronica Caesaraugustana, remonta à deposição de Esteban, governador da Hispânia em nome do ostrogodo Teodrico durante a menoridade de Amalarico, por uma assembleia em Gerona, em 529. Sabemos, por Isidoro de Sevilha que, após a derrota de Amalarico em Narbona, o exército reunido executou o rei, o que para o autor sinalizaria uma congregação nacional dos homens livres armados regressados de uma campanha desastrosa em 531.

Ou seja, para Sánchez-Albornoz, a transformação institucional goda reduziu, com o passar das décadas, o papel das assembleias como espaço de resolução de conflitos e aclamação régia. Entretanto, as mudanças não Ihes teriam apagado, sendo novamente convocada por Wamba na cidade régia após a derrota imposta aos vascões e ao insurgente duque Paulo. Para o autor, a reunião promovida por Wamba seria o mais tardio indício da manutenção das reuniões de homens livres, na qual o monarca reúne o conjunto dos senhores do palácio, eclesiásticos e exército. Ainda que SánchezAlbornoz afirme que o oficio palatino seja algo novo, em sua opinião, seria muito descabido não relacioná-lo àquelas reuniões germânicas conhecidas desde a antiguidade.

Sánchez-Albornoz alia a manutenção das tradições históricas da antiga Germânia a um paulatino processo de imitação bizantina e herança romana, sugerindo essas origens para a organização palaciana. Algo que mais ou menos reforça a difundida ideia de incapacidade dos germanos de produzirem algo próprio... Ora, não seria mais razoável entender a sociedade visigoda como fruto de seu próprio desenvolvimento histórico, sem recuar numa busca das "origens", cujos perigos já nos advertira Marc Bloch (2001: 65-68)? Desejo avançar neste sentido, configurando o chamado officium palatinum como entidade intimamente relacionada à estruturação social visigoda, como uma instituição influenciada pelas relações sociais de produção desse momento histórico e que, por sua vez, retroagiu sobre as mesmas.

Assim, creio que não se trata da mera herança de assembleias antigas que já guardariam poucas semelhanças com aquelas realizadas no século $V$ e, possivelmente, sem qualquer grau de correspondência com o contexto visigótico dos séculos VI a VII. Afinal, como procurei demonstrar em outras oportunidades, as sociedades germânicas passaram por intensos processos de hierarquização social que progressivamente minaram a base "igualitária" que as configuravam nos tempos de Júlio Cesar e Tácito. Dessa 
forma, as várias evidências elencadas por Sánchez-Albornoz talvez apontem menos para uma reunião horizontal dos homens livres e cada vez mais para uma elite - ligada ao monarca por laços hierárquicos de fidelidade - que ia à guerra acompanhada de seus dependentes armados.

Outra questão necessária de ser abordada no trabalho desse autor diz respeito à forma como avalia a relação entre a aristocracia e o poder régio insistindo numa intrínseca e sistemática oposição entre monarquia (Mo) e nobreza (No), ${ }^{2}$ como se fossem entes antagônicos. Trata-se de perspectiva seguida por significativa parcela dos historiadores espanhóis, inclusive pela enorme influência de Sanchéz-Albornoz. Esse modelo MoNo, perspicazmente identificado na historiografia por Paulo Pachá, se tornou hegemônico justamente por ser "invisível", ou seja, por não ser explicitado ou mesmo objeto de reflexão pelos autores. Consequentemente, levando o conflito entre monarquia e "nobreza" a se firmar como eixo explicativo das disputas na sociedade visigoda de maneira mais ou menos acrítica (Pachá, 2015: 23-47).

O conflito entre esses polos opostos seria evidenciado pelas perseguições que reis como Leovigildo ou Chindasvinto teriam perpetrado, tornando os membros da aristocracia cada vez menos numerosos (Sánchez-Albornoz, 1971: 175-176). Dessa forma, o palácio seria então uma forma da pujante monarquia visigoda atrair para si os relativamente poucos aristocratas menos hostis, controlá-los e fazer com que desempenhassem as funções que interessavam ao poder régio (Sánchez-Albornoz, 1971: 178). Para isso, seriam concedidos cargos (Sánchez-Albornoz, 1971: 181) e títulos honoríficos que poderiam ou não desempenhar funções efetivas (Sánchez-Albornoz, 1971: 131-132), o que, em outras palavras, mais parece reproduzir, inadequadamente, um sistema de cortes extemporâneo.

A reunião do conjunto aristocrático, para Sánchez-Albornoz, se daria então naquilo que a documentação chama de aula regia. A qual não seria tão constante, pois muitos viveriam fora do Palácio e pelo fato de ser formada por tantos membros que seria demasiado grande para uma assembleia. Sendo constituida tanto pelos seniores

\footnotetext{
${ }^{2}$ Faço, costumeiramente, a opção deliberada de não utilizar o termo "nobreza", por ser uma classificação demasiadamente subjetiva e vaga, fazendo a escolha de usar o termo "aristocracia" que para mim seria mais preciso, se traduzindo no controle sobre terras e trabalho. Para uma discussão a esse respeito, vide (Morsel, 2008: 12-14). O modelo chamado MoNo aparece aqui com o termo "nobreza" por sintetizar de forma adequada a forma como os historiadores tem operado, usando ambos os vocábulos como sinônimos.
} 
palatii, dos quais muitos residiam na corte, os proceres que viveriam próximos ao rei, os comites, bem como os oficiais do Officium Palatinum (Sánchez-Albornoz, 1971: 242). Ainda contando com a presença de uma série de oficiais subalternos que não compareciam ao consilium do rei. Precisamente por essa complexidade e heterogeneidade que o autor defende que deveria existir, no seio do palácio, um conselho e tribunais reais formados pelos altos dignatários do Officium.

Afinal, de onde viria essa tão brutal oposição explicitada pelo modelo MoNo se tanto aristocratas quanto reis eram membros da mesma classe? Há que se recolocar esse conflito de maneira mais operacional para ser capaz de explicar as disputas internas à classe dominante visigoda, fugindo dessa simplificadora dicotomia.

Outro elemento que precisa ser repensado diz respeito à própria constituição dessa classe, uma vez que, havia grupos terratenentes poderosos e bastante diversos na Hispânia visigoda. Grupos esses que, certamente, não seriam redutíveis aos membros do officium palatinum ou da aula regia, como veremos mais adiante a partir das referências documentais.

Outro importante estudo, de Isla Frez (2002), acorda em diversos pontos com a análise desenvolvida por Sánchez-Albornoz. Poderíamos citar, por exemplo, a perspectiva de que o palatium fosse formado por uma diversidade de estatutos sociais. Além disso, ambos defendem que haveria uma divisão do palácio em níveis, um mais amplo, formado por um grande setor da aristocracia e dependentes, e outro mais restrito àqueles imediatamente próximos ao rei.

Contudo, ambos os autores discordam sobre um elemento central, que determina a própria função do chamado palácio e está diretamente relacionado à distinta forma como ambos encaram a relação entre aristocracia e monarquia. Enquanto o primeiro, como vimos, supervaloriza o poder régio e avalia que os cargos ou a proximidade aristocrática do palácio funcionavam como elementos de dominação e controle da aristocracia pelos reis, o segundo reavalia essa posição. Para Isla Frez, o chamado officium palatinum não é composto por delegados reais, mas pela mais poderosa aristocracia visigoda, em um espaço de tentativa de construção de consenso. Desse modo, o palácio seria uma instância primária da (re)produção coletiva da aristocracia, seja no estabelecimento de consenso ou na elaboração legislativa.

A proposição de Isla Frez me agrada, pois dá "coletividade" à monarquia, tiran- 
do o foco de apenas um indivíduo onipotente e passando-o aos dinâmicos agentes coletivos que são as classes em suas disputas internas e entre si. Ainda que esse autor potencialmente esteja longe de uma perspectiva marxista, podemos, com base nessa interpretação, dar coerência teórica ao presente estudo. Escapar-se-á, assim, da dicotômica relação MoNo, configurando o palatium como instância privilegiada de disputa e de criação de consenso, articulando a fração dominante da aristocracia.

Articulação que pode ser vista a partir de uma análise da documentação ${ }^{3}$ desde períodos relativamente precoces. No III Concílio de Toledo de 589 temos a mais remota alusão à existência de um laço entre os setores dominantes da aristocracia quando da apostasia do arianismo ${ }^{4}$ feita pelo rei Recaredo, bispos, religiosos e os maiores natu primoresque gentis Gothicae. ${ }^{5}$ Ou seja, além dos eclesiásticos arianos convertidos, um conjunto de laicos da alta aristocracia associada ao monarca também se converteu à ortodoxia e subscreveu as decisões conciliares (Vives, 1963: 123). Mesmo não aparecendo explicitamente na ata o termo palatium ou officium palatinum, fica claro que havia uma articulação entre setores aristocráticos e o rei, os quais de maneira mais ou menos consensual com o resto da classe ratificaram a conversão formal do reino.

Apesar de não considerar a antinomia entre arianismo e catolicismo uma secção essencial no seio da aristocracia - uma vez que ambas se reproduziam a partir das mesmas bases materiais, i.e., a exploração do campesinato - é possível ver a unidade

\footnotetext{
${ }^{3}$ Aqui privilegiarei as fontes, especialmente normativas, dos séculos VI e VII. Ainda que fosse de grande utilidade acompanhar em uma longa duração a evolução das reuniões visigodas, como fez SánchezAlbornoz, elas escapam ao recorte proposto a esse trabalho. Contudo, reforço o que já destaquei ao debater o trabalho do referido autor, ao longo do século $V$ é pouco provável que se mantivessem assembleias similares àquelas do tempo de Tácito dada a grande verticalização social que se produziu desde a redação da obra Germania, principalmente depois do assentamento na Gália e na Hispânia. Além disso, as fontes citadas por Sánchez-Albornoz parecem ser demasiadamente vagas para que ele produza afirmações tão categóricas sobre a origem na tradição germânica dessas reuniões. A Crônica de Hidácio, uma das referências de Sánchez-Albornoz que pude dedicar alguma atenção, por exemplo, faz apenas uma menção vaga - provavelmente referindo-se ao ano de 467 - ao concilium dos godos que não permite identificar claramente quem dele fazia parte (Burgess, 1993: 120). Imagino, contudo, se não seria mais coerente com o processo de desenvolvimento da aristocracia germana, supor que se tratasse uma reunião da classe dominante e não de todo o povo. Proposição que encontra suporte na lei 323 do Código de Eurico, ratificado em época próxima aos eventos narrados por Hidácio, a qual permite ver que iam à guerra senhores acompanhados de seus dependentes, não mais o conjunto dos homens livres.

${ }^{4}$ Desde antes de seu assentamento na Gália ou na Hispânia os visigodos, assim como outros povos germânicos, já tinham formalmente se convertido ao cristianismo, contudo, seguiam uma vertente chamada arianismo, considerada herética pela ortodoxia católica adotada no Império Romano. Para uma abordagem da sociedade visigoda sob o arianismo (Thompson, 2007: 17-133).

5 "[...] episcopus et religiosos vel maiores natu ex haerese Arriana conversos [...]." (Vives, 1963: 117); e "[...] episcopi omnes una cum clericis suis primoresque gentis Gothicae [...]." (Vives, 1963: 118).
} 
religiosa como um projeto de construção de consenso. Projeto esse que foi avançado por Leovigildo em torno do arianismo, mas que se conclui apenas com seu sucessor e filho, Recaredo, em torno da ortodoxia (Castellanos, 2007). Ou seja, uma tentativa de evitar fracionamentos que levaram a uma revolta como a de Hermenegildo, irmão mais velho de Recaredo, claramente vinculado às frações católicas da aristocracia.

Seria válido avançar a hipótese, ainda que isso exceda os objetivos do presente trabalho, de que a chamada "Guerra Civil" deflagrada por Hermenegildo foi produto do próprio movimento de Leovigildo - e do grupo próximo a ele - que gerou um desequilíbrio na classe dominante. Instabilidade surgida do favorecimento dos setores arianos, com doações e privilégios fiscais e administrativos, levando à disputa aberta entre as frações aristocráticas. Afinal, a proximidade ao cargo régio dava aos setores próximos a ele a capacidade de reprodução expansiva necessária à manutenção de suas posições de poder frente ao conjunto da classe.

Outro indício da articulação do grupo dominante da aristocracia com o rei pode ser encontrada no cânone 75 do Concílio de Toledo IV, celebrado em 633, no qual lêse:

Ninguém estimule as discórdias civis, nem trame a morte dos reis, mas sim que, morto pacificamente, os primatus totius gentis, em união com os bispos, designarão de comum acordo o sucessor ao trono, para que se conserve por nós a concórdia da unidade, e não se origine alguma divisão da pátria e do povo por conta da violência e da ambição. ${ }^{6}$

Nesse trecho, podemos observar, além da evidência de conflitos e disputas abertas e tramas no interior da aristocracia pelo trono, que os maiores do reino deveriam escolher o futuro rei. Ou seja, há uma tentativa de construção de consenso no seio da aristocracia para a escolha do sucessor régio. Contudo, cabe perguntar, quem seriam os eleitores que participariam dessa votação junto aos bispos?

Para Sánchez-Albornoz, no Concílio de Toledo IV ainda vigorariam assembleias do conjunto da aristocracia, as quais teriam sido constantemente constrangidas pelo

\footnotetext{
6 “[...] nullus excitet mutuas seditiones civium; nemo meditetur interitus regum, sed defuncto in pace principe primatus totius gentis cum sacerdotibus successorem regni concilio conmuni constituant, ut dum unitatis concordia a nobis retinetur, nullum patriae gentisque discidium per vim atque ambitum oriatur." (Vives, 1963: 270).
} 
poder dos reis (Sánchez-Albornoz, 1971: 172). Algo que, para esse autor, evoluiria até que somente os bispos e os maiores do palácio pudessem votar na eleição de um rei, como vemos no cânone 10 das atas do VIII Concílio de Toledo, celebrado em 653 (Vives, 1963: 283). Todavia, não creio que houvesse diferenças significativas entre os potenciais eleitores nos vinte anos que separam ambos os concílios.

Afinal, a própria instituição palaciana já existia desde princípios do século VII como espaço de articulação social da facção aristocrática reinante. Isso fica claro com base na lei que proibia os judeus de possuírem libertos, servos ou escravos sob sua dependência, ${ }^{7}$ adicionada ao Liber Iudicum no ano de 612 pelo rei Sisebuto junto ao chamado ofício palatino. ${ }^{8}$ Ademais, em 636 , apenas três anos depois do concílio anterior celebrado na cidade régia, o de Toledo $\mathrm{V}$, o rei Chintila adentra a reunião acompanhado dos maiores do palácio. ${ }^{9}$ Parece-me, desse modo, factível avançar que o palácio se constituía como a primeira instância de construção de acordos no seio da aristocracia, pelo menos desde começos do século VII, ainda que seja bastante provável que ao longo do VI não tenha sido diferente. Esta primeira instância articulava as frações dominantes reunidas em torno do monarca, ou seja, os primatus totius gentis do Toledo IV, ou mesmo os maiores natu primoresque gentis Gothicae do Toledo III.

Podemos ver também que a associação do grupo dominante se manteve importante para resolução de questões de grande importância no seio da aristocracia visigoda ao longo da história do Reino de Toledo. Como nos conta a Historia Wambae Regis, de Julião, futuro bispo de Toledo, à época do rei Recesvinto os maiores do palácio o acompanharam na guerra contra os vascões e cântabros. Quando da morte do monarca, ainda durante essa campanha, Wamba é escolhido pelos maiores palacianos como soberano, em acordo com as deliberações conciliares anteriormente abordadas. Importante notar também que o novo rei tenha frisado que esperaria chegar à cidade régia para que o bispo the impusesse as mãos, favorecendo com essa ação um maior tempo para a construção de consenso entre a aristocracia, evitando que fosse visto

\footnotetext{
7 "nulli Hebreo ab anno regni nostri feliciter primo christianum liberum vel servum mancipium in patrocinio vel servitio suo habere [...]" In LV, 12, 2, 14.

8 "Ob hoc hac in perpetuum valitura lege sanccimus adque omni cum palatino officio futuris temporibus instituentes decernimos" In LV, 12, 2, 14.

9 "[...] gloriosi principis nostri Chinthilani regis initia, ob cuius salutis et felicitatis constantiam supernam inploramus clementiam, qui medio nostri coetus ingressus cum obtimatibus et senioribus palatii sui [...]" (Vives, 1963: 226).
} 
como um usurpador (Hillgarth, 1976: 220-221). ${ }^{10}$

Julião de Toledo nos conta também que enquanto Wamba ainda fazia guerra na Cantábria, chegaram notícias de uma rebelião na região da Narbonense encabeçada por Ilderico, conde da cidade de Nîmes. Esse conde, representante do poder aristocrático local, associado a eclesiásticos como Gumildo, bispo de Maguelonne, e o abade Ramiro - posteriormente feito bispo de Nîmes pelos insurgentes ${ }^{11}$ - se levanta no contexto de transição monárquica (Hillgarth, 1976: 221). Ao saber do ocorrido, Wamba envia o duque Paulo para controlar a revolta; este, contudo, ao invés de combatê-la se associa a ela e a Ranosindum, duque da Tarraconense (Hillgarth, 1976: 223), proclamando-se, em carta que envia a Wamba, o "ungido rei do leste". ${ }^{12}$

Para fazer frente a essa rebelião, Wamba reuniu os primates palatii a fim de decidir se o melhor seria marchar direto da Cantábria à Narbonese ou reagrupar um exército mais adequado para lutar contra os revoltosos (Hillgarth, 1976: 224-226). Mais uma vez, temos indícios da importância dessa instituição, definindo junto ao rei a forma de proceder em situações de crise. Em outras palavras, é possível observar como nesse contexto as frações dominantes mais próximas ao rei se articulam da melhor forma contra outras que desejam disputar o cargo régio.

Mais adiante, ainda na Historia Wambae Regis, após o duque Paulo ter sido derrotado e trazido à cidade de Toledo, inicia-se o seu julgamento e de seus apoiadores. Entre aqueles que lutaram ao seu lado pode se contar uma série de bispos ${ }^{13}$ e membros da alta hierarquia do clero, ${ }^{14}$ além de membros da alta aristocracia local (HILLGARTH, 1976: 253) e, inclusive, indivíduos que provavelmente haviam participado do officium palatinum. ${ }^{15}$ Para julgá-los foram "[...] convocados e reunidos todos nós, a saber, senhores do palácio, gardingos ${ }^{16}$ e o ofício palatino, na presença de todo o exér-

\footnotetext{
${ }^{10}$ Wamba normalmente é visto pela historiografia como um rei "forte" que se impôs a "nobreza", como já destaquei essa oposição não permite compreendamos de maneira adequada os conflitos entre as frações de classe e a construção de acordos. Para uma análise da ascensão de Wamba ao trono que deixa de lado o modelo MoNo vide (Pachá, 2015: 117-121).

${ }^{11}$ Aregio, bispo de Nîmes, se recusou a tomar parte na revolta e foge da região (Hillgarth, 1976: 221).

12 "[...] unctus rex orientalis [...]" (Hillgarth, 1976: 217).

${ }^{13}$ Aparecem no julgamento Jacinto da cátedra de Llivia; o "falso" prelado de Nîmes, Ramiro; Wilesindo, provavelmente bispo de Adge; Gumildo, a frente do bispado de Maguelone (Hillgarth, 1976: 251-253).

${ }^{14}$ Gultricián que era primiclericum, cargo de alta estatura na hierarquia católica (Hillgarth, 1976: 251253).

${ }^{15}$ Euredo, o qual participou do Concílio de Toledo VIII, celebrado em 653, provavelmente como comes et prócer tendo sido um dos viri ilustres officii palatini. (Hillgarth, 1976: 251-253).

${ }^{16}$ Há um grande debate etimológico sobre o significado do termo gardingus, mas ao que tudo indica
} 
cito, sob a supervisão de nosso senhor com os seus sócios mais próximos." ${ }^{17}$

Aqui, percebe-se que o próprio exercício da justiça, ao menos quando diz respeito ao conjunto da aristocracia, é também tomado como uma ação coletiva na qual se busca consenso entre os setores aristocráticos dominantes vitoriosos. Dentro desse conjunto, inclusive, deveriam figurar bispos e religiosos, já que, ao longo de toda a narrativa, Julião parece se constituir como um autor/espectador dos eventos que descreve. Talvez a distinção dos termos senioribus cunctis palatii e palatino officio presentes no julgamento venha denotar a existência de "círculos" no interior do palácio, com proximidade diferenciada com relação ao monarca.

Tendo isso em mente, pode se afirmar com alguma segurança que a articulação dos setores dominantes da classe aristocrática no palácio integrava também os que se mantinham em proximidade com o monarca mesmo não ocupando cargos. A articulação palaciana, dessa maneira, excederia, e muito, os comites e duces, figurando nela também aqueles que estavam diretamente ligados à domesticidade régia por laços de vassalagem, como os gardingi e os praedicti socii. Oferece-nos um testemunho nesse sentido o cânone 13 do VI Concílio de Toledo, celebrado em 633, que diz explicitamente que compõem o palácio aqueles de alta dignidade e os que estão próximos ao rei (Vives, 1963: 241).

Uma lei de Égica, em fins do século VII, ajuda a iluminar essa diferença de círculos de proximidade no palácio, ao denotar que havia membros do ofício palatino que não habitavam a corte e se demoravam em comparecer perante o rei para lhe jurar fidelidade. ${ }^{18}$ Ora, que nem todos os membros do ofício palatino residissem na corte é bastante razoável dado a inscrição local dos poderes aristocráticos, mas a opção deliberada por não irem perante o rei sugere a existência de relações de aliança permeadas por tensões. ${ }^{19}$ Tensões que, não pouco frequentemente, levavam à ruptura dos

derivaria de gards, uma palavra de origem germana que equivaleria ao termo latino domus, ou seja, "casa". Em outras palavras, é possível vê-los como os membros da aristocracia diretamente ligados ao soberano por laços vassálicos, estando, pois, sob sua domesticidade. Para mais informações vide (Isla Frez, 2002: 845-847) e (Sánchez-Albornoz, 1971: 201-205), para esse autor os gardingos na origem seriam um prolongamento histórico do comitatus germano e só após as doações reais passaram a estar ligados a terra.

17 "[...] conucatis adunatisque omnibus nobis, id est senioribus cunctis palatii, gardingis omnibus omnique palatino officio, seu etiam adstante exercitu uniuerso, in conspectu gloriosi nostri domni cum praedictis sociis [...]" (Hillgarth, 1976: 253-254).

${ }^{18} \mathrm{LV}, 2,1,7$.

${ }^{19}$ Essa resistência dos aristocratas se apresentarem perante o príncipe ou bispo metropolitano, explici- 
laços sociais que uniam as frações dominantes da aristocracia ao rei, laços que ao serem rompidos se recompunham com outros grupos. Algo evidenciado não só pelo fato de que quase todos os monarcas que assumiram o trono no século VII terem feito parte, anteriormente, do palácio (Isla Frez, 2002: 829), mas pela própria revolta de Paulo.

Esse duque integrava o ofício palatino e havia jurado fidelidade à Wamba (Hillgarth, 1976: 222-223), mas, ao se rebelar contra o rei que havia sido eleito, é possível ver que ele se rearticula com outros poderosos locais de forma a garantir de maneira mais vigorosa a sua reprodução e daqueles aristocratas que a ele se vincularam. Dessa forma, ao invés de subverter a existência da monarquia, cria novos laços com outra parcela da classe aristocrática, exigindo deles a fidelidade que Wamba lhe havia exigido (Hillgarth, 1976: 223). ${ }^{20}$

O inverso, por sua vez, também é verdadeiro, havendo grandes aristocratas que exerceram o poder local e que escaparam à articulação palaciana, algo que a própria história da revolta do duque Paulo também permite entrever. Afinal, como já apontei, Paulo se associou a poderes condais que se levantaram em Nîmes, ao duque da Tarraconense e a uma série de altos membros do clero.

Nesse sentido, também são esclarecedores o cânone 2 do XIII Concílio de Toledo (Vives, 1963: 418-419), ${ }^{21}$ celebrado em 683 - que ficou conhecido na historiografia como "habeas corpus" visigodo - ou a lei acrescida ao Liber ludicum por Chindasvinto $^{22}$, que tratava do wergeld. ${ }^{23}$ Foram estabelecidas condições privilegiadas para os membros do ofício palatino ${ }^{24}$, preservados de castigos corporais e encarceramento,

tando sua relação de inferioridade perante um superior, também pode ser vista desde os tempos de Ervígio através do cânone VIII do concílio de Toledo XIII (Vives, 1963: 424-425).

${ }^{20}$ A importância dos laços de fidelidade para a organização da aristocracia como classe, bem como de suas frações, é evidenciada em uma série de referências documentais para além da Historia Wambae Regis, como, para citar apenas alguns exemplos, o cânone 75 de Toledo IV; o cânone 2 de Toledo X, durante o Concílio de Toledo XIV os bispos discutem longamente sobre o juramento de fidelidade que Égica havia prestado a Ervígio; o cânone 10 de Toledo XVI é outra evidência (Vives, 1963: 217-218, 310, 441-448, 509-512).

${ }^{21}$ Vide também LV, 12, 1, 3.

${ }^{22}$ LV, 6, 1, 2, lei de Chindasvinto que se manteve na Lex Visigothorum até suas últimas versões, com algumas modificações feitas por Ervígio.

${ }^{23}$ Tratava-se da compensação pecuniária em caso de cometer um crime, como homicídio, a fim de evitar vinganças intermináveis. Na LV , 6, 1, 2, vemos o privilégio que membros do ofício palatino tinham, sendo por eles oferecidas uma composição pecuniária maior. Para mais informações sobre o wergeld no contexto visigodo (Sánchez-Albornoz, 1993: 197-207).

${ }^{24}$ Outro elemento de privilégio dos membros do ofício palatino que poderia ser citado estava relacionado aos dotes, podendo exigir e oferecer dotes maiores que o resto dos aristocratas. Observa-se isso em LV , 3, 1, 5, acrescida ao código por Chindasvinto e se mantendo até suas últimas versões com al- 
bem como do confisco de bens, e destacados por soldos mais elevados se assassinados. Contudo, esses privilégios se apresentam com um duplo significado, sinalizando tanto o destaque daqueles que compõem as frações mais próximas ao monarca quanto o risco a que as mesmas estavam submetidas. Afinal, caso outros grupos acessassem o trono, seriam os prováveis primeiros alvos de expropriação das novas facções empoderadas.

Entretanto, continuou sendo lícito ao príncipe afastar dos cargos aqueles que julgasse incapazes para exercer a administração, desde que sem Ihes causar infâmia. Ora, esse julgamento do rei sobre a "incapacidade" daquele que exerce o cargo é permeado por altas doses de subjetividade, parecendo uma forma do monarca manter controle sobre a dignidade condal, de juiz, duque, etc. Todavia, esse cânone deixa ainda transparecer que havia membros que exerciam cargos em desacordo com aquilo que atendia aos interesses do monarca, estando distantes do soberano e possivelmente fora da articulação mais próxima do rei. Dessa maneira, reunido esse conjunto de elementos, não creio que houvesse necessária correspondência entre o exercício de funções administrativas - em âmbito local ou regional - e a presença no palácio

O conflituoso consenso manifesto na articulação palaciana também pode ser observado no ato do perdão régio, como pode se verificar numa das leis adicionadas ao Liber ludicum por Chindasvinto, a qual submete a misericórdia do monarca à aprovação dos sacerdotum maiorumque palatii, ou seja, dos bispos e dos grandes do palácio. ${ }^{25}$ Medida importante de ser analisada, pois permite entrever, em algum nível, a dinâmica aristocrática, em que a misericórdia real implicava no restabelecimento de integrantes da classe dominante. O retorno à antiga condição social vinha com a devolução das propriedades que haviam sido confiscadas, acirrando, assim, a já ferrenha disputa intra-aristocrática pelo controle de terras e trabalho.

Essa norma se efetiva na realidade quando o Concílio de Toledo XIII perdoa, a pedido de Ervígio (Vives, 1963: 413), aqueles que participaram da tentativa de usurpação do trono de Wamba associados ao duque Paulo. Os bispos e os maiores do palácio concordam em perdoar não só aos partidários do duque Paulo, mas também todos aqueles acusados de traição desde o rei Chintila, restaurando suas propriedades na

${ }^{25} \mathrm{LV}, 6,1,7$. 
medida do possível (Vives, 1963: 415-416). Não à toa essa ressalva é feita, somente sendo permitido devolver os bens que não tivessem sido doados pelo rei a terceiros, mantendo-se vinculados ao fisco régio. Ou seja, nenhum tipo de expropriação deveria ser feita a fim de devolver aos traidores seus antigos bens, os quais deveriam vir exclusivamente do patrimônio associado ao monarca.

, qual seria o tamanho do palatium? Quantos aristocratas o comporiam? Em primeiro lugar, cabe ressaltar que essa permanência era em larga medida temporária dada a circunscrição local dos poderes aristocráticos. A proximidade com o poder régio constituía-se numa forma de reforçar na localidade os aristocratas, como elemento de distinção social e pelo acesso a presentes que perpetuavam a relação de fidelidade. Ainda que seja difícil precisar quantos seriam os membros da fração dominante que orbitavam em torno do rei, podemos estimar que fossem bastante numerosos com base nos poderes episcopais. Os bispos, grandes aristocratas locais, com controle sobre - além do seu patrimônio pessoal - o conjunto de propriedades da Igreja vinculado a sua sé, ${ }^{26}$ foram limitados pelo cânone 4 do Concílio de Toledo VII a viajar com comitiva de no máximo cinquenta pessoas (Vives, 1963: 254-255). Se cinquenta é o teto fixado pelo sínodo, imagine-se a quantidade de membros que acompanhavam os bispos em suas visitas na diocese trazendo problemas a diversas paróquias. Tendo o poder monárquico expressão peninsular, é lícito, portanto, imaginar que deveriam compor o palácio algumas centenas de aristocratas. Estes seriam aqueles que perfaziam a fração dominante da aristocracia, dispostos em círculos de proximidade variada com o rei e, dessa forma, distintamente beneficiados pela relação com o soberano. Isso sem contar o conjunto de livres com menor projeção social - porventura pequenos aristocratas sob domesticidade régia direta, os tais medíocres (Orlandis, 1991: 37-38) que aparecem na lei antijudaica de Ervígio. ${ }^{27}$ Além de pessoas de condição servil, dependentes

\footnotetext{
${ }^{26}$ Ainda que houvesse igrejas empobrecidas e com poucos dependentes, como denota o cânone XIX do Concílio de Mérida ou tomus régio e os cânones V e VI do Concílio de Toledo XVI (Vives, 1963: 338$339,502)$, o conjunto do patrimônio de uma sé era bastante vasto. Se tomarmos por outro lado o patrimônio da abadia de Dúmio, que possivelmente foi o maior da Península Ibérica visigoda, vemos que esse possuía sozinho bem mais do que quinhentos dependentes a ele vinculado, como demonstra o decreto anexado às atas do Concílio de Toledo $X$ que revoga o testamento de Ricimiro. $O$ controle sobre o patrimônio eclesiástico era tão importante para aristocracia que surgiram verdadeiras "famílias eclesiásticas". Possivelmente, o exemplo mais conhecido dessas "dinastias" sejam os irmãos Isidoro e Leandro que se sucederam no bispado de Sevilha, e que ainda tiveram mais um irmão, Fulgêncio, bispo de Écija e uma irmã, Florentina, abadessa (Orlandis, 1991: 31-32).

${ }^{27} \mathrm{LV}, 12,2,15$.
} 
do monarca ou do fisco, que ocupariam funções de pouca expressão, como fiscais locais ou administradores do patrimônio régio. ${ }^{28}$

Isto posto, a proposição que agora avanço é de que comporiam o palácio as frações aristocráticas que têm no rei a sua expressão mais evidente, e que se valiam da proximidade do cargo régio para garantir a sua ascendência frente as outras frações rivais. Essa articulação do grupo dominante da aristocracia funcionava, então, como o primeiro elemento de construção de consenso na aristocracia. Contudo, defendendo essa perspectiva, não pretendo avançar uma interpretação funcionalista na qual a sociedade ou determinados espaços dela funcionam em coordenada harmonia. Pelo contrário, estou especialmente interessado nos conflitos e frequentes rearranjos de alianças no seio da aristocracia que constantemente se redesenhavam.

Assim sendo, entender o palatium como uma forma de articulação de frações da classe dominante permite fugir da falsa dicotomia que opõe monarquia e aristocracia, vendo-os não como opostos, mas entes similares, inseridos nas mesmas relações de produção/dominação. Além disso, permite escapar de outras interpretações que seguem, implícita ou explicitamente, um individualismo metodológico, que veem a aristocracia como um conjunto de membros isolados que disputam entre si de forma autofágica.

Por conseguinte, creio ter deixado claro que os conflitos não são estranhos ao sistema social visigodo ou um "efeito colateral" do seu funcionamento, mas que, ao contrário, fazem parte da sua dinâmica tendo-se em vista as disputas de facções da classe dominante que buscavam garantir seu poder e reprodução. Em outras palavras, as várias frações aristocráticas rivalizavam entre si a fim de assegurar acesso crescente a recursos limitados, tais como terra e trabalho para sua consequente redistribuição. Acumulação e fracionamento que materializavam as relações de fidelidade entre os aristocratas, as quais eram necessárias para manter a posição social de cada aristocrata individualmente, e de suas frações. Participar da articulação dominante garantia acesso privilegiado a instrumentos de poder oriundos da proximidade ao cargo régio, tanto do fisco quanto daqueles obtidos através da aplicação da justiça ou conquista

\footnotetext{
${ }^{28}$ Pode-se entrever esses dados a partir das referências contidas no Concílio de Toledo XIII tanto no chamado tomus régio como no cânone VI (Vives, 1963: 413-414, 422-423). É interessante notar que, apesar de possuírem condição servil, os dependentes que exerciam funções no palácio tinham privilégios em relação aos demais, possuindo o direito de testemunhar. In LV, 2, 4, 4.
} 
militar. Explicam-se, assim, as constantes tentativas de tomada do trono, não como indício de um Estado frágil e pouco legítimo, mas da disputa de um mecanismo de reprodução em meio a uma lógica sistêmica conflituosa e coerente.

\section{Fontes Primárias}

BURGESS, R. W.. 1993. The Chronicle of Hydatius and the Consularia Constantino politana - Two Contemporary Accounts of the Final Years of the Roman Empire. Oxford: Clarendon Press.

HILLGARTH, J. N. (org.). 1976. Sancti Ivliani Toletanae sedis episcopi Opera. Pars I. Tvrnholti: Brepols (Corpus Christianorum - Series Latina, CXV).

VIVES, J.; et al (eds.). 1963. Concílios Visigóticos e Hispano-Romanos. BarcelonaMadrid: CSIC.

ZEUMER, K.. 1902. Leges Visigothorum. Hannoverae/Lipsiae, Imprensis Bibliopolii Hahniani (Monumenta Germaniae Historica. Leges NatiorumGermanicarum, vol. I).

\section{REFERÊNCIAS}

CASTELLANOS, S.. 2007. Los godos y la Cruz. Madrid: Alianza.

BERNARDO, J.. 1995. Poder e Dinheiro - Do Poder Pessoal ao Estado Impessoal no Regime Senhorial, séculos $V-X V$, parte 1. Porto: Edições afrontamento.

BLOCH, M.. 2001. Apologia da história, ou O ofício do historiador. Rio de Janeiro: Jorge Zahar Ed.

CODATO, A. N.; PERISSINOTO, R.. 2001. O Estado como instituição. Uma leitura das "obras históricas" de Marx. Crítica Marxista, v.1, n.13.

DAFLON, E.. 2016. Articulando o Estado: Campesinato e Aristocracia na Hispânia Visigótica (Séculos VI-VIII). Niterói, RJ, (Mestrado). Universidade Federal Fluminense.

DAFLON, E.. 2014. O Processo de Hierarquização Social Germana (Séculos I a.C.-II d.C.). In BASTOS, M..; et al (orgs.). O Pré-Capitalismo em Perspectiva: estudos em homenagem ao prof. Ciro F. S. Cardoso. Rio de Janeiro, Ítaca Edições.

DÍAZ, P. C.. 2012. Confiscations in the Visigothic Reign of Toledo - A Political Instrument. In PORENA, P., RIVIÈRE, Y.. Expropriations et Confiscations dans les Royaumes Barbares - Une Approche Régionale. Roma: École française de Rome.

FRIED, M.. 1976. A evolução da sociedade política. Rio de Janeiro: Zahar Editores.

GARCÍA MORENO, L. A.. 1974. Estudios sobre la organización administrativa del reino de visigodo de Toledo. Anuario de Historia del Derecho Español, série 1, n 1.

ISLA FREZ, A.. 2002. El Officium Palatinum Visigodo - Entorno Régio y Poder Aristocrático. Hispania, LXII/3, num. 212.

LE GOFF, J.. 2005. A Civilização do Ocidente Medieval. Bauru: EDUSC.

MORSEL, J.. 2008. La Aristocracia Medieval- El Dominio Social em Occidente (Siglos V$X V)$. Valência: Universidade de Valência.

ORLANDIS, J.. 1991. La Vida en España en Tiempo de los Godos. Madrid: Ediciones Rialp.

PACHÁ, Paulo. 2015. Estado e Relações de Dependência Pessoal no Reino Visigodo de Toledo (Séculos VI-VII). Niterói, RJ, (Doutorado). Universidade Federal Fluminense. 
SAHLINS, M.. 1974. Sociedades Tribais. Rio de Janeiro: Zahar Editores.

SÁNCHEZ-ALBORNOZ, C.. 1971. El Aula Regia y las Asambleas Politicas de los Godos. Estudios visigodos. Roma: Istituto Storico Italiano per il Medio Evo.

SÁNCHEZ-ALBORNOZ, C.. 1993. En torno a los Orígenes del feudalismo. Madrid: Ediciones Istmo.

THOMPSON, E. A.. 2007. Los godos en España. Madrid: Alianza Editorial 